\section{Neoplasia de sigma de presentación infrecuente}

\author{
Unusual presentation of colorectal \\ neoplasia
}

Mujer de 73 años que consulta por dolor abdominal. En la exploración física se objetiva temperatura de $38,5^{\circ} \mathrm{C}$, hipotensión, taquicardia, eritema en hemiabdomen derecho, dolor abdominal difuso y crepitación a la palpación en fosa ilíaca derecha. Durante su estancia en sala el eritema se va tornando violáceo (Figura 1). En la analítica se objetiva leucocitosis y elevación importante de los reactantes de fase aguda. Se realiza TAC abdominal en el que se objetivan signos de fascitis y miositis necrotizante de pared abdominal derecha y engrosamiento parietal en unión rectosigmoidea, sugerente de neoplasia (Figuras 2 y 3). Se instauró tratamiento antibiótico con Meropenem y Linezolid y se realizó desbridamiento inmediato, confirmándose la presencia de neoplasia en sigma perforada. La paciente ingresó en la UVI, falleciendo días después. En los cultivos obtenidos durante la cirugía crecieron E. faecium y E. coli. La perforación intestinal en el cáncer colorrectal ocurre entre un 3,7\% y un 7,8\% de los casos, presentando una elevada mortalidad ${ }^{1,2}$. Sin embargo, se han publicado muy pocos casos de fascitis necrotizante como presentación de carcinoma colorectal1,2. La flora responsable de la infección suele ser mixta aerobia-anaerobia.

\section{Bibliografía}

1. Ku HW, Chang KJ, Chen TY, Hsu CW, Chen SC. Abdominal necrotizing fasciitis due to perforated colon cancer. J Emerg Med. 2006; 30:95-6.

2. Marron CD, McArdle GT, Rao M, Sinclair S, Moorehead J. Perforated carcinoma of the caecum presenting as necrotising fasciitis of the abdominal wall, the key to early diagnosis and management. BMC Surg. 2006; 6:11.

\section{Diagnóstico: Fascitis necrotizante como presentación de cáncer colorrectal}

Ismael Calero Paniagua ${ }^{1}$, Andrés Julián Plata Izquierdo²

${ }^{1}$ Servicio de Reumatología, ${ }^{2}$ Servicio de Medicina Interna. Hospital Universitario de Salamanca. SACYL. Salamanca

Correspondencia: ismaelcaleropaniagua@yahoo.es

Como citar este artículo: Calero Paniagua I, Plata Izquierdo AJ

Neoplasia de sigma de presentación infrecuente Galicia Clin 2014; 75 (4): 205

Recibido: 13/04/2014; Aceptado: 10/07/2014
Figura 1. Eritema violáceo en hemiabdomen derecho, con crepitación a la palpación

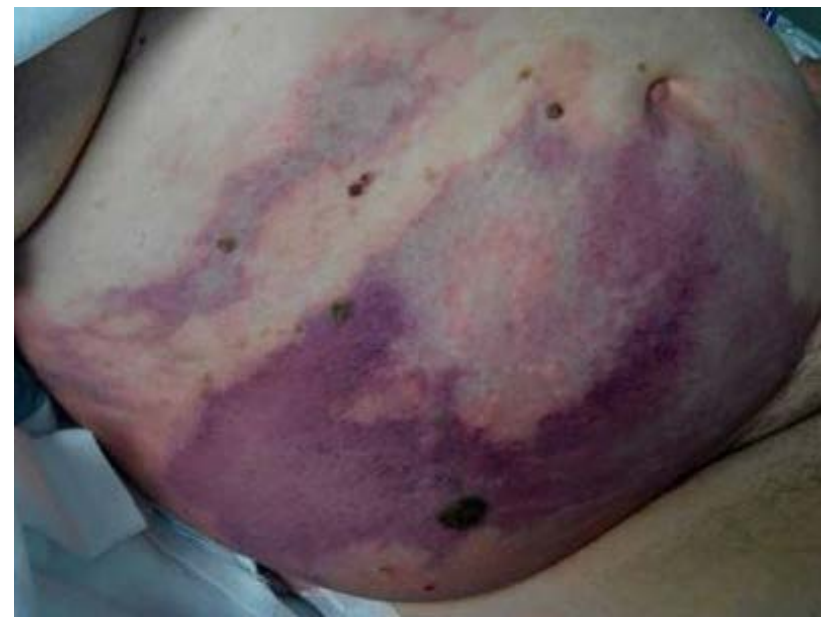

Figura 2. Fascitis y miositis necrotizante de pared abdominal

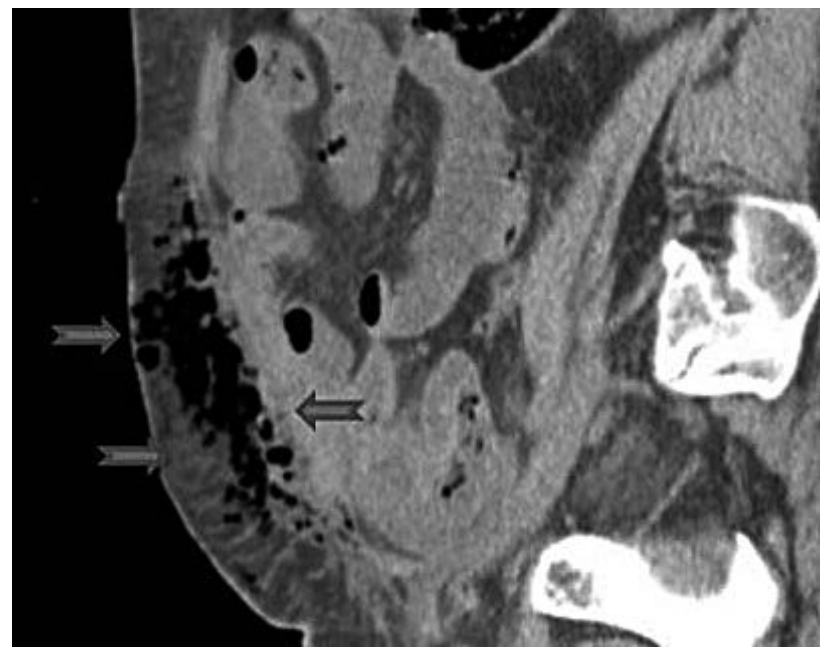

Figura 3. Fascitis y miositis necrotizante de pared abdominal

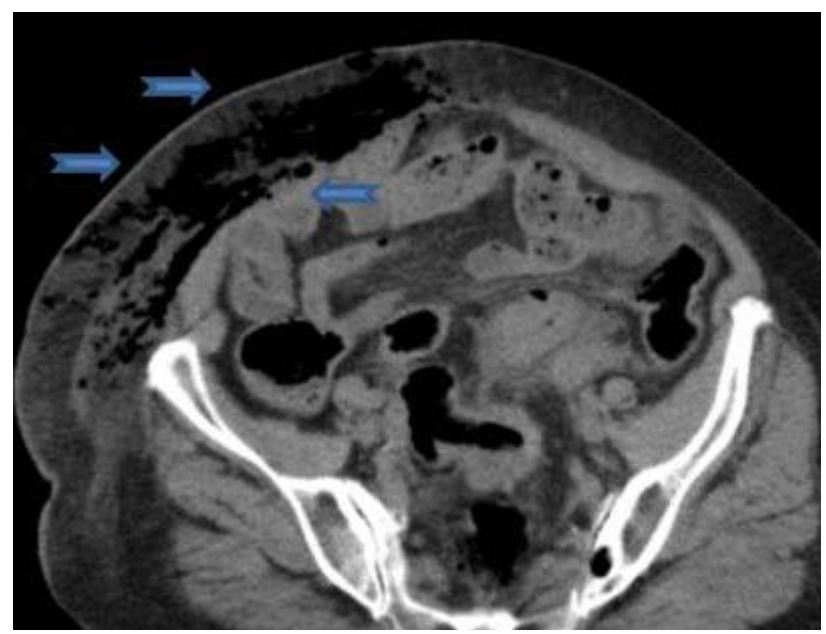

